\title{
Accuracy of Various Creatinine Based Prediction Equations For Estimating Glomerular Filtration Rate in Prospective Donors in Comparison to DTPA Renogram.
}

\author{
Dr Dineshan $\mathrm{KM}^{1}$, Dr Aditya Shenoy ${ }^{2}$, Dr Felix Cardoza ${ }^{3}$ \\ ${ }^{1}$ Additional Professor.Department Of Urology, Govt.Medical College, Kozhikode, Kerala \\ ${ }^{2}$. Resident. Corresponding Author .Department Of Urology, Government Medical College, Kozhikode, Kerala \\ ${ }^{6}$ Head Of The Department .Department Of Urology, Government Medical College, Kozhikode, Kerala
}

\begin{abstract}
Objectives: A noninvasive and accurate estimation of GFR is one of the holy grails of renal function evaluation. We analysed accuracy of CKD Epidemiology Collaboration (CKD-EPI), Modification of Diet in Renal Disease (MDRD) and Mayo Clinic Quadratic (MCQ) equations to estimate GFR with reference to a standard GFR obtained by DTPA renal scan.

Methods: Between June 2011 and June 2013, healthy adults underwent DTPA renal clearance studies as part of a routine work-up for potential kidney donation. 70 subjects had sufficient data to estimate GFR-including age, gender, Creatinine (Cr) \{based on average of 2 values obtained 2 weeks apart performed at the same hospital lab\}.

Results: Mean GFR obtained by DTPA, CKD-EPI, MDRD and MCQ were 93.4 $\pm 13.4,86.94 \pm 14.8,83.0 \pm 17.6$ and $104.5 \pm 10.27 \mathrm{ml} / \mathrm{min} / 1.73 \mathrm{~m} 2$ respectively. All equations correlated well with DTPA-GFR $(p<0.01)$. The bias and mean absolute difference in $\mathrm{ml} / \mathrm{min}$ per $1.73 \mathrm{~m} 2$ between calculated and measured GFR for CKD-EPI, MDRD, MCQ were -6.57 and $11.03,-10.45$ and $14.75,+11.1$ and 14.13 respectively. Percentage of values within $30 \%$ and $50 \%$ of predicted in each equations were - CKD-EPI: $71.4 \% ; 91.4 \%$, MDRD: $51.4 \% ; 81.4 \%$, MCQ: $57.1 \%$; $81.4 \%$.

Conclusion: CKD-EPI had least bias and was more accurate within 30 and 50\% of the measured GFR even though it frequently under estimated measured GFR. MCQ equation (developed for patients with preserved renal function) had least bias in subset of measured GFR $>90 \mathrm{ml} / \mathrm{min}$. In potential donors, these equations may not be sufficient for estimating GFR. Further studies are needed to derive prediction equations in Indians with normal renal function.
\end{abstract}

Keywords: ESRD , Renal Transplantationn, GFR, DTPA Renogram, Mayo Clinic Formula ,CKD-EPI formula , MDRD formula., Accuracy, Creatinine .

\section{Introduction}

Although kidney transplantation offers a favourable outcome for the recipient, it may be associated with some risk for the donor.Renal function assessment of the donor is the most important part of donor evaluation.Glomerular Filtration Rate(GFR) is considered to be optimal test for overall assessment of renal function.GFR can be precisely measured by specific filtration markers such as Inulin, I-125 Iothalamate, $\mathrm{Cr} 51$ EDTA, Tc99-DTPA.Non invasive and accurate estimation of GFR is the need of the hour.Here comes the utility of GFR prediction equations which are easy to apply, cost effective and less cumbersome.

GFR estimation with DTPA- Plasma sample method, Gamma camera uptake method (Gates Formula).The Tc-99m-DTPA is reported to overestimate GFR by $3.5 \mathrm{ml} / \mathrm{min}$ in average as compared to the renal clearance of inulin as a golden GFR marker. ${ }^{1}$ GFR is the volume of fluid filtered from the glomerular capillaries into the Bowman's capsule per unit time.Estimated Glomerular Filtration Rate, usually is based on serum Creatinine level, age, sex, and race. Estimates of creatinine clearance based on the serum creatinine level (at a steady state in our body) are used to measure GFR.It is freely filtered by the glomerulus, but also actively secreted by the peritubular capillaries in very small amounts.

\section{Timeline}

1976, Cockcroft-Gault equation, which actually estimates creatinine clearance rather than GFR. 1999, Modification of Diet in Renal Disease (MDRD) study equation was published. 2002, followed by the "abbreviated" four variable MDRD equation, which was widely adopted.2004, Mayo Quadratic formula was developed by Rule et al to better estimate GFR in patients with preserved kidney function 2009, The CKD-EPI (Chronic Kidney Disease Epidemiology Collaboration) formula (more accurate when actual GFR is greater than $60 \mathrm{~mL} / \mathrm{min})$ 
Mdrd equation: "4-variable MDRD," which estimates GFR using four variables: serum creatinine, age, ethnicity, and gender ${ }^{2}$.However both MDRD versions underestimate the GFR in healthy patients with GFRs over $60 \mathrm{~mL} / \mathrm{min}$ For creatinine in $\mathrm{mg} / \mathrm{dl}: 186 \times[\mathrm{Pcr}]-^{1.154} \times[$ age $]-{ }^{0.203} \times[0.742$ if patient is female $]$

\section{Mayo Quadratic Formula .}

$\mathrm{GFR}=\exp (1.911+5.249 / \mathrm{SCr}-2.114 / \mathrm{SCr} 2-0.00686 \times$ Age $-(0.205$ if Female $))$ If $\mathrm{SCr}<0.8 \mathrm{mg} / \mathrm{dL}$, use 0.8 $\mathrm{mg} / \mathrm{dL}$ for $\mathrm{SCr}$.

Developed by Mayo clinic in an attempt to better estimate GFR in patients with preserved kidney function.Performed better than MDRD in patients with good GFR. ${ }^{3}$

\section{Ckd-Epi Equation}

Chronic Kidney Disease Epidemiology Collaboration - 2009

If serum creatinine $(\mathrm{Scr})<=0.7 \mathrm{GFR}=144 \times(\mathrm{SCr} / 0.7)-0.329 \times 0.993 \mathrm{Age}$

If serum creatinine $(\mathrm{Scr})>0.7 \mathrm{GFR}=144 \times(\mathrm{SCr} / 0.7)-1.209 \times 0.993 \mathrm{Age}$

If serum creatinine $(\mathrm{Scr})<=0.9 \mathrm{GFR}=141 \times(\mathrm{SCr} / 0.9)-0.411 \times 0.993 \mathrm{Age}$

If serum creatinine $(\mathrm{Scr})>0.9 \mathrm{GFR}=141 \times(\mathrm{SCr} / 0.9)-1.209 \times 0.993 \mathrm{Age}$

Researchers pooled data from multiple studies to develop and validate this new equation. ${ }^{4}$ They used 10 studies that included 8254 participants, randomly using 2/3 of the data sets for development and the other $1 / 3$ for internal validation

Objectives : To analyse the accuracy of CKD Epidemiology Collaboration (CKD-EPI), Modification of Diet in Renal Disease (MDRD) and Mayo Clinic Quadratic (MAYO) equations to estimate GFR with reference to a standard GFR obtained by DTPA renal scan. To explore if any of these can replace the more expensive DTPA method in potential renal donors.

\section{Methods}

Retrospective analytical study done during June 2011 -2013. In Department of Urology,Calicut medical college Inclusion criteria:

Healthy adults undergoing DTPA renal clearance studies as part of a routine work-up for potential kidney donation. 70 subjects had sufficient data to estimate GFR-including age, gender, Creatinine $(\mathrm{Cr})$ \{based on average of 2 values obtained 2 weeks apart performed at the same hospital lab .

\section{Exclusion Criteria :}

Patients with incomplete results / creatinine measured from other labs. Those with creatinine measurements varying more than 0.1 between 2 samples. Creatinine> 1.2 for females and 1.4 for males.

Patients with any abnormalities on USG / DTPA studies.

$\mathrm{BMI}>30$

GFR measurements were averaged and standardized for a BSA of $1.73 \mathbf{~ m}^{2}$.

Bias is the mean prediction error:Bias = eGFR- DTPA GFR

Mean absolute Difference $=$ [eGFR- DTPA GFR $]$

Relative Bias $=$ Percentage mean absolute difference . (Mean absolute GFR x 100)/ DTPA GFR

SPSS 18 for Windows (Chicago,IL) was used for all statistical calculations- except the Bland - Altman plot for concordance derived from MedCalc Statistical Software version 12.7.8 (Ostend, Belgium)

\section{Results}

The study included Males $(\mathrm{n}=32)$ and Females $(\mathrm{n}=38)=1: 1.18$

Table 1 .Demographic analysis

\begin{tabular}{|l|l|l|l|l|l|l|}
\hline & AGE & Cr & DIPA & CKDEPA & MDAD & MAYO \\
\hline MEAN & 44.11 & 0.88 & 93.46 & 86.94 & 83.04 & 104.5 \\
\hline STD DEV & 8.33 & 0.14 & 13.44 & 14.84 & 17.67 & 10.27 \\
MIN & 22 & 0.6 & 72 & & & \\
MAX & 58 & 1.3 & 123 & & & \\
& & & & & & \\
\hline
\end{tabular}


Table 2 . Correlations with gfr - pearsons

\begin{tabular}{lll}
\hline CKDEPI & & Pval \\
MDRD & 0.58 & 0.01 \\
MAYO & 0.51 & 0.01 \\
\hline
\end{tabular}

Table 3. Measures of accuracy

\begin{tabular}{|l|l|l|l|}
\hline Milmin PER m & & $\begin{array}{l}\text { MEAN } \\
\text { ABSOLUTE } \\
\text { DIFFERENCE }\end{array}$ & $\begin{array}{l}\text { STD DEV } \\
\text { (STD ERROR: }\end{array}$ \\
\hline CKDEPI & -6.57 & 11.03 & $9.44(1.13)$ \\
MDRD & -10.45 & 14.75 & $11.8(1.4)$ \\
MAYO & +11.11 & 14.13 & $9.44(1.14)$ \\
\hline
\end{tabular}

Table 4. Bias and mean absolute difference

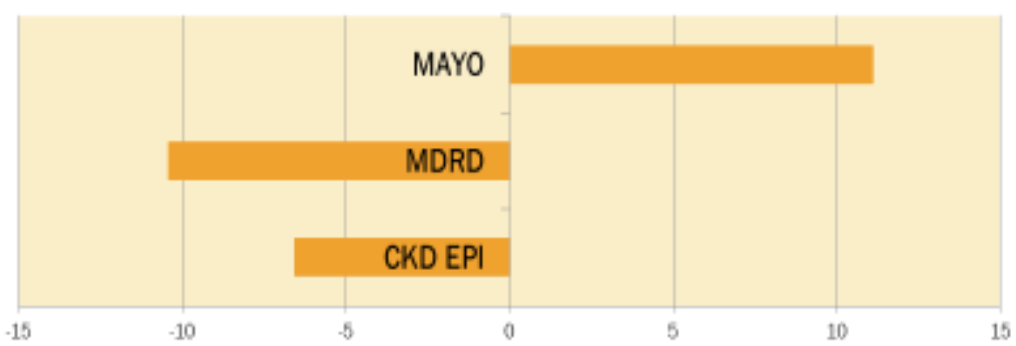

Table 5 . Percentage mean absolute difference and numbers within a range

\begin{tabular}{|l|l|l|l|}
\hline $\begin{array}{l}\text { ML/MIN } \\
\text { PER M }\end{array}$ & $\%$ MAD & $\begin{array}{l}\% \text { WITHIN } \\
30 \%\end{array}$ & $\begin{array}{l}\% \text { WITHIN } \\
50 \%\end{array}$ \\
\hline CKDEPI & $11.68 \pm 9.6$ & $71.4 \%(50)$ & $91.4 \%(64)$ \\
\hline MDRD & $15.39 \pm 11.8$ & $51.4 \%(36)$ & $81.4 \%(57)$ \\
\hline MAYO & $16.30 \pm 13.3$ & $57.14 \%(40)$ & $81.4 \%(57)$ \\
\hline
\end{tabular}

Though trend towards lesser bias was seen with CKD-EPI and MDRD in males compared with female population, the mean absolute differences were similar and the reverse was seen with MAYO. Although all equations performed irrespective of age CKD-EPI had the best accuracy and least bias. CKD-EPI was most accurate in GFR $<90 \mathrm{ml} / \mathrm{min}$ while MAYO equation performed marginally better at higher GFR values The results are displayed in tables below. 
MALE

\begin{tabular}{|c|c|c|c|c|c|}
\hline$N=32$ & MEAN & RANGE & $N=38$ & MEAN & PANGE \\
\hline AGE & $45.8 \pm 9.3$ & $30-59$ & & $43.4 \pm 8$ & 22.56 \\
\hline $\mathrm{Cr}$ & $0.96 \pm .14$ & $0.6-1.3$ & & $0.83 \pm .14$ & $0.6-1$ \\
\hline GFR & $94.4 \pm 14$ & $76-123$ & & $91.2 \pm 13.3$ & $72-120$ \\
\hline $\mathrm{MV} / \mathrm{min} / \mathrm{m}^{7}$ & BUS & MAD & & BIAS & MAD \\
\hline CKDEPI & -3.2 & 9.2 & & -8.6 & 12.0 \\
\hline MDRD & -4.6 & 13.6 & & -12.2 & 15.22 \\
\hline MAYO & +16.3 & 22.4 & & +8.5 & 12.33 \\
\hline
\end{tabular}

AGE $<50$

\begin{tabular}{|c|c|c|c|c|c|}
\hline$N=43$ & MEAN & PANCE & $\mathrm{N}=27$ & MEAN & BANGE \\
\hline$A G E$ & 39.6 & $22-49$ & & 53.08 & 50.59 \\
\hline Cr & $0.82 \pm 0.14$ & & & $0.88 \pm 0.19$ & \\
\hline GFR & $95.5 \pm 13.8$ & & & $88.4 \pm 10.6$ & \\
\hline $\mathrm{M} / \mathrm{min} / \mathrm{m}^{2}$ & BIAS & XMAD & & BUS & KMAD \\
\hline CKDEPI & -6.5 & 12.4 & & -5.2 & 11.04 \\
\hline MDRD & -11.8 & 15.9 & & -6.9 & 14.28 \\
\hline MAYO & +11.4 & 17.6 & & +11.8 & 16.22 \\
\hline
\end{tabular}

$$
\text { GFR }>90
$$ \\ GFR $>90 \quad$ GFR $<90$}

\begin{tabular}{|c|c|c|c|c|c|}
\hline $\mathrm{N}=40$ & MEAN & RANGE & $\mathrm{N}=30$ & MEAN & RANGE \\
\hline $\mathrm{Cr}$ & $0.84 \pm 0.18$ & 0.61 .1 & & $0.91 \pm 0.12$ & $0.7-1.3$ \\
\hline GFR & $101.8 \pm 9.9$ & $90-123$ & & $81.6 \pm 6.5$ & $72-89.9$ \\
\hline $\mathrm{M} / \mathrm{min} / \mathrm{m}^{2}$ & BIAS & \%MAD & & BIAS & \%MAD \\
\hline CKDEPI & -9.35 & 12.69 & & -3.1 & 10.9 \\
\hline MDRD & -12.23 & 17.18 & & -7.5 & 13.07 \\
\hline MAYO & +8.5 & 11.88 & & +15.3 & 24.2 \\
\hline
\end{tabular}

Figure 1 .Bland Altman Analysis of Concordonce between CKD EPI and DTPA GFR.

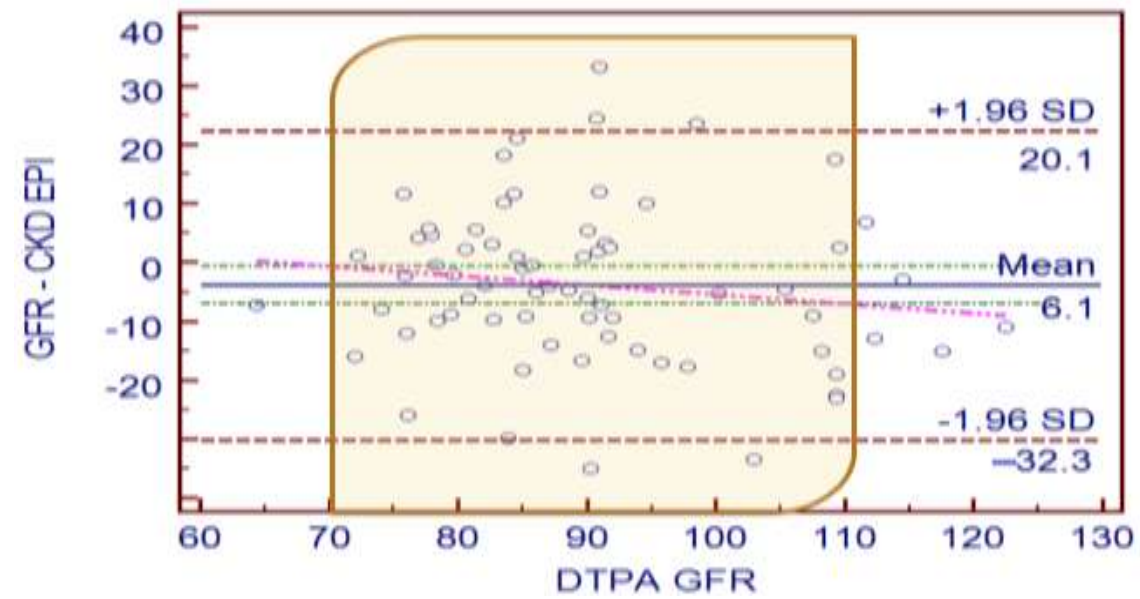

Figure 2 .Bland Altman Analysis of Concordonce between MDRD and DTPA GFR. 


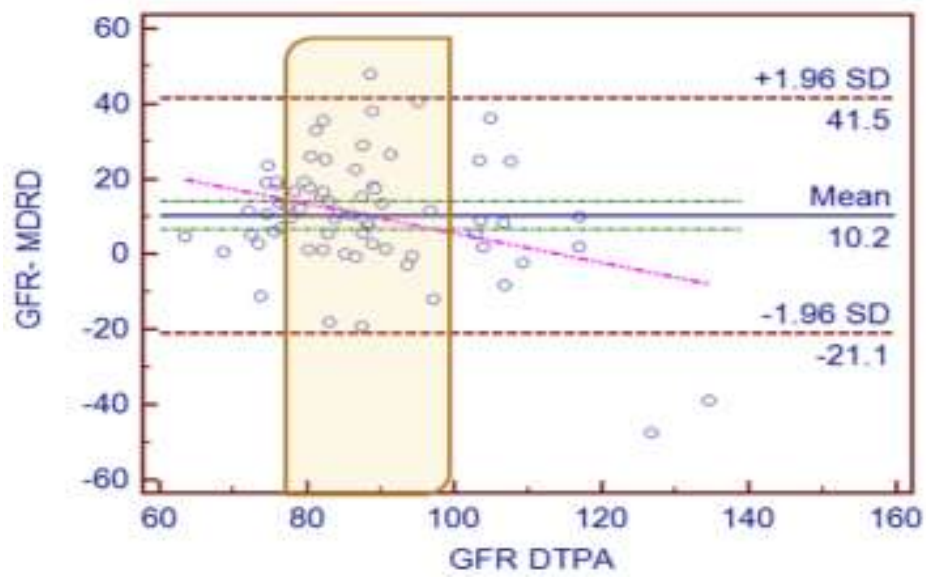

Figure 3. Bland Altman Analysis of Concordonce between Mayo and DTPA GFR.

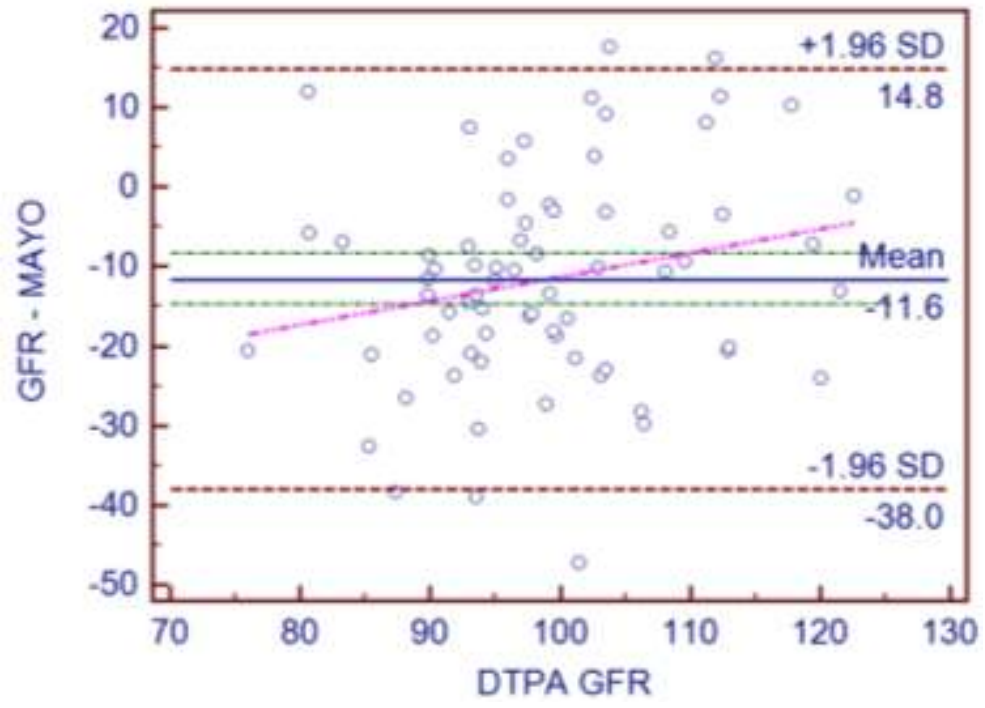

III. Discussion

Mean GFR obtained by DTPA, CKD-EPI, MDRD and MCQ were 93.4 $\pm 13.4,86.94 \pm 14.8,83.0 \pm 17.6$ and $104.5 \pm 10.27 \mathrm{ml} / \mathrm{min} / 1.73 \mathrm{~m} 2$ respectively. All equations correlated well with DTPA-GFR ( $<<0.01$ ). The bias and mean absolute difference in $\mathrm{ml} / \mathrm{min}$ per $1.73 \mathrm{~m} 2$ between calculated and measured GFR for CKD-EPI, MDRD, MCQ were -6.57 and $11.03,-10.45$ and $14.75,+11.1$ and 14.13 respectively. Percentage of values within $30 \%$ and $50 \%$ of predicted in each equations were - CKD-EPI: $71.4 \%$; $91.4 \%$, MDRD: $51.4 \% ; 81.4 \%$, MCQ: $57.1 \% ; 81.4 \%$.

All equations correlated well with DTPA-GFR ( $\mathrm{p}<0.01$ ).Of all equations CKD EPI had least bias, \% mean absolute difference and had highest $\%$ of values predicted within $30 \%$ as well as $50 \%$ of measured GFR.CKD EPI and MDRD showed a negative bias overall compared to MAYO quadratic equation.All equations performed with similar accuracy across age, gender groups.

Limitations of the study includes : Relatively small cohort., Cystatin-C has recently been projected to be a more accurate measure than creatinine, Ideal proportions of subjects across sex, age groups not present..DTPA- GFR though accurate enough, its comparison with inulin clearance not validated in large cohorts

\section{Conclusion}

In potential donors, these equations may not be sufficient for estimating GFR. CKD EPI appears to be most useful at present and its underestimation of actual GFR is safer during preliminary work up.Donors on the lower end of values for eGFR may be selectively subjected to accurate tests.Further studies are needed to derive prediction equations in Indians with normal renal function 


\section{References}

[1]. Rehling M, et al. Simultaneous measurement of renal clearance and plasma clearance of 99mTc-labelled DTPA, 51Cr-labelled EDTA and inulin in man. Clin Sci 1998; 66: 613-619.

[2]. Bosch JP et al, A more accurate method to estimate glomerular filtration rate from serum creatinine: a new prediction equation. Modification of Diet in Renal Disease Study Group. Ann Intern Med. 1999 Mar 16;130(6):461-70.

[3]. Néstor Fontseré et al, Is the New Mayo Clinic Quadratic Equation Useful for the Estimation of Glomerular Filtration Rate in Type 2 Diabetic Patients? Diabetes Care. 2008 December; 31(12): 2265-2267.

[4]. Levey AS, Stevens LA, A new equation to estimate glomerular filtration rate. Ann Intern Med. 2009 May 5;150(9):604-12. 